\title{
Pre-Operative, Prophylactic Use of Oral Zinc Tablet in the Management of Post-Operative Sore Throat
}

\author{
Ketki Jandial $^{1}$, Shagufta Tabassum² \\ ${ }^{1}$ Medical Officer, Super Specialty Hospital, GMC Jammu, J\&K \\ ${ }^{2}$ Resident, Department of Anesthesiology and Critical Care, GMC Jammu, J\&K \\ Corresponding Author: Ketki Jandial
}

\begin{abstract}
Background: Postoperative sore throat (POST) is considered to be quite common complaint. Its symptoms tend to improve with time, but use of oral zinc lozenge has been shown to reduce the incidence and severity of POST. The aim of the present study was to find the efficacy of oral zinc sulfate, given 30 min preoperatively, in reducing POST, primarily caused by endotracheal intubation, till 24 hours after surgery.
\end{abstract}

Method: A prospective, randomized, doubleblinded, placebo-control-trial study was conducted on 80 patients, further divided into two groups of 40 patients each, between the age group of 18-60 years, of either gender, in Super Specialty Hospital, GMC Jammu, over a period of 6-months. The two groups received either dispersible zinc tablet or a placebo. The severity of POST was graded on a 4-point scale ranging from 0 to 3 and evaluation was repeated at 30 min, 2, 4, and 24 hour, postoperatively.

Results: The difference in severity of sore throat was found to be statistically significant at all evaluation time intervals, except at 24 hours, which was quite lower in Zinc group. The overall incidence of POST in Zinc group was $26.3 \%$, which was significantly higher at $50 \%$ in placebo group.

Conclusion: A dose $40 \mathrm{mg}$ zinc dispersible tablet, equivalent to $40 \mathrm{mg}$ elemental zinc, given 30 min before surgery, effectively reduced the incidence and severity of POST.

Key Words: Post Operative Sore Throat, Oral Zinc Lozenge, Endotracheal Intubation

\section{INTRODUCTION}

Common issues and complaints of patients receiving general anaesthesia include: nausea and vomiting, sore throat or hoarseness, dry mouth, shivering or chills, sleepiness, muscle aches, difficulty urinating, ileus etc. Postoperative sore throat (POST) is considered to be quite common complaint. ${ }^{[1,2]}$ Itimproves with time, however any intervention to prevent it may improve patient satisfaction and may impact discharge from hospital. Several of such pharmacological and non-pharmacological remedies have been tried over the time, with varying degree of success. ${ }^{[3,4]}$ Use of oral zinc lozenge has been shown to reduce the incidence and severity of POST. ${ }^{[5]}$

Zinc as a micronutrient, is known to promote growth and tissue repair. Zinc is also helpful in modulating immune system. It has been used for prevention of oral mucositis in patients receiving high dose chemotherapy. [6,7] Prophylactic use of topical magnesium also has been shown to prevent POST due to its anti-inflammatory properties. ${ }^{[8]}$

There is minimum literature and studies available pertaining to the effects of zinc on POST in Indian population, therefore, the aim of the present study was to find the efficacy of oral zinc sulfate, given 30 minutes preoperatively, in reducing POST, primarily caused by endotracheal intubation, till 24 hours after surgery. The dispersible tablet form of zinc was preferred due to its easy availability and known effect on oropharyngeal mucosa. 


\section{MATERIALS AND METHODS}

A prospective, randomized, doubleblinded, placebo-control-trial study was conducted on a total of 80 patients, in Super Specialty Hospital, GMC Jammu, over a period of 6-months. The study group was further divided into two groups with age and gender-matched 40 patients each. A written informed consent was obtained from all participants. Ethical approval was duly obtained from institutional ethical committee. Randomization, for selection, was achieved using computer-generated random code number and sealed envelope method to create separate two groups to receive either dispersible zinc tablet or a placebo. The code was maintained till the completion of study.

\section{Inclusion Criteria:}

Patients between the age group of 18 to 60 years were included.

Patients with ASA Physical Status of I and II, posted for low to moderate risk surgeries of duration greater than $1 \mathrm{~h}$ and less than 6$\mathrm{h}$ duration, were included in the study.

\section{Exclusion Criteria:}

Smokers, pregnant patients, patients with a recent history of sore throat or upper respiratory tract infection, Mallampati grade (MPG) greater than II and patients with allergy to zinc were excluded from the study.

A specific surgical duration was chosen to ensure that the patient was intubated long enough to cause irritation of oropharyngeal mucosa.

After written informed consent, a sealed and coded envelope with either zinc or placebo tablets was given to the patient, with instruction to dissolve the tablet in mouth 30 min prior to surgery. The zinc group received zinc sulfate tablets, equivalent to $40 \mathrm{mg}$ elemental zinc, as was commercially available. The control group received placebo tablets with no active ingredient but was indistinguishable in appearance and taste from the one containing zinc. The investigators and the patients alike were blinded about the content of the envelope and the code was maintained until the completion of the study.

Till the patient was sucking on the provided dispersible tablet, all kinds of sedative medications were held back. Premedication included injection ranitidine (50 mg iv), inj. ondansetron (4 mg iv). After 3 min of preoxygenation, anaesthetic induction was commenced with intravenous tramadol $1 \mathrm{mg} / \mathrm{kg}$ and propofol $2 \mathrm{mg} / \mathrm{kg}$ followed by orotracheal intubation facilitated by atracurium $0.5 \mathrm{mg} / \mathrm{kg}$.

Laryngoscopies were performed on both groups and laryngoscopic view of glottis was classified using CormackLehane classification. Duration of laryngoscopy (time from opening mouth to the placement of the endotracheal tube) and the intubation time (the interval between the insertion of the laryngoscope blade into the mouth to the inflation of the endotracheal tube cuff) was recorded in all patients. The cuff pressure of the endotracheal tube was adjusted every $30 \mathrm{~min}$, using a handheld pressure gauge and maintained between 20 and $22 \mathrm{~cm}$ of $\mathrm{H} 2 \mathrm{O}$.

Anesthesia was maintained with $1.1 \%$ isoflurane in $60 \% \mathrm{~N} 2 \mathrm{O}$ and $40 \% \mathrm{O} 2$ mixture, intermittent fentanyl and atracurium at $0.15 \mathrm{mg} / \mathrm{kg}$ was used when required. The use of steroids and antiinflammatory drugs was recorded. The patients were extubated upon completion of surgery following careful suctioning of the oropharynx and were transferred to the Post Anesthesia Care Unit (PACU).

During emergence from anesthesia, any coughing or bucking was duly noted. On arrival at PACU, immediate evaluation for presence and severity sore throat was done (time $=0$ ), using a standardized scale. Side effects such as nausea, vomiting, metallic taste, and diarrhea were also noted.

The severity of POST was graded on a 4-point scale ranging from 0 to 3; 0 being no sore throat, 1 being mild discomfort (complaints only upon questioning), 2 being moderate sore throat (complains of his/her 
Ketki Jandial et.al. Pre-operative, prophylactic use of oral zinc tablet in the management of post-operative sore throat.

own), and 3 being severe sore throat (change in voice, hoarseness and throat pain). The evaluation was repeated at 30 min, 2, 4, and $24 \mathrm{~h}$.

Based upon previous studies, ${ }^{[9,10]}$ the incidence of POST was presumed to be $65 \%$, power at $80 \%$, alpha error at 0.05 ; only 36 patients in each group were required to detect a $50 \%$ reduction in the incidence of POST. Assuming drop out at $10 \%, 40$ patients in each group were included, making the total sample size 80 .

Statistical Methods: Data was analyzed using Microsoft Excel-2010 software. All categorical variables were expressed as number and percentage, whereas the continuous variables were expressed as mean \pm standard deviation. Patient demographics and the incidence of POST between groups were compared using the Chi-square test. The $\mathrm{P}$ value $<0.01$ was considered significant.

\section{RESULTS}

A total of 80 patients who gave consent were enrolled and were randomly allocated, 40 to zinc group and 40 to placebo group. Two patients each in zinc group and placebo group required more than one attempt at intubation and were excluded from the study. Thus, data from 76 patients were available for analysis: 38 from zinc group and 38 from placebo group. Both groups were found be comparable in regards of demographic variables. (Tables 1 )

Table 1: Demographic Characteristics of Patients

\begin{tabular}{|l|l|l|l|}
\hline & Zinc group (n=38) & Placebo group (n=38) & p-value \\
\hline Age (years) (mean \pm SD) & $38.23 \pm 9.66$ & $38.80 \pm 9.72$ & 0.767 \\
\hline Weight $(\mathrm{kg})($ mean \pm SD) & $66.58 \pm 7.96$ & $67.08 \pm 8.12$ & 0.252 \\
\hline Gender Ratio (male/female) $\mathrm{n}$ & $21 / 17$ & $20 / 18$ & 0.831 \\
\hline$\%$ & $(55 \% / 45 \%)$ & $(53 \% / 47 \%)$ & \\
\hline ASA PS* (I/II) n & $27 / 11$ & $25 / 13$ & 0.132 \\
\hline$\%$ & $(71 \% / 29 \%)$ & $(66 \% / 34 \%)$ & \\
\hline
\end{tabular}

*ASA PS - American Society of Anesthesiologists Physical Status.

Table 2: Incidence of POST at different evaluation times

\begin{tabular}{|l|l|l|l|}
\hline Evaluation time & Incidence in Zinc group (n=38) & Incidence in Placebo group (n=38) & p-value \\
\hline At 0 min & $2(5.3 \%)$ & $9(23.7 \%)$ & $0.0071^{*}$ \\
\hline At $30 \mathrm{~min}$ & $4(10.5 \%)$ & $12(31.6 \%)$ & $0.0034^{*}$ \\
\hline At 2 hours & $3(7.9 \%)$ & $13(34.2 \%)$ & $0.0006^{* *}$ \\
\hline At 4 hours & $3(7.9 \%)$ & $12(31.6 \%)$ & $0.0012^{*}$ \\
\hline At 24 hours & $10(26.3 \%)$ & $12(31.6 \%)$ & 0.088 \\
\hline \multicolumn{2}{|r|}{$* P<0.01$ = significant. $* * P<0.001=$ highly significant } &
\end{tabular}

Table 3: Severity of POST at different evaluation times

\begin{tabular}{|c|c|c|c|c|c|c|c|}
\hline \multirow{2}{*}{ Evaluation Time } & \multicolumn{3}{|c|}{ Zinc group (n=38) } & \multicolumn{3}{|c|}{ Placebo group $(n=38)$} & \multirow{2}{*}{ p-value } \\
\hline & Mild & Moderate & Severe & Mild & Moderate & Severe & \\
\hline At 0 min & $2(5.3 \%)$ & 0 & 0 & $7(18.4 \%)$ & $2(5.3 \%)$ & 0 & $0.0072 *$ \\
\hline At $30 \mathrm{~min}$ & $4(10.5 \%)$ & 0 & 0 & $10(26.3 \%)$ & $2(5.3 \%)$ & 0 & $0.0039 *$ \\
\hline At 2 hours & $3(7.9 \%)$ & 0 & 0 & $8(21.1 \%)$ & $4(10.5 \%)$ & $1(2.6 \%)$ & $0.0007 * *$ \\
\hline At 4 hours & $1(2.6 \%)$ & $2(5.3 \%)$ & 0 & $3(4.5 \%)$ & $6(15.8 \%)$ & $3(7.9 \%)$ & $0.0011^{*}$ \\
\hline At 24 hours & $7(18.4 \%)$ & $3(7.9 \%)$ & 0 & $7(18.4 \%)$ & $3(7.9 \%)$ & $2(5.3 \%)$ & 0.1304 \\
\hline
\end{tabular}

Table 4: Overall incidence with respect to severity of POST

\begin{tabular}{|l|l|l|l|}
\hline & Zinc group $(\mathrm{n}=38)$ & Placebo group $(\mathrm{n}=38)$ & $\mathrm{p}$-value \\
\hline Mild POST & $7(18.4 \%)$ & $6(15.8 \%)$ & .873 \\
\hline Moderate POST & $3(7.9 \%)$ & $10(26.3 \%)$ & $0.026^{*}$ \\
\hline Severe POST & $0(0 \%)$ & $3(7.9 \%)$ & 0.241 \\
\hline Overall Incidence & $10(26.3 \%)$ & $19(50 \%)$ & $0.015^{*}$ \\
\hline \multicolumn{4}{|l}{} \\
\hline
\end{tabular}

The incidence of POST between groups was found to be statistically significant at all evaluation time intervals, except at 24 hours. (Table 2)

The severity of POST was also found significantly lower in Zinc group than
Placebo group. No statistically significant difference was found in severity of POST between groups at $24 \mathrm{~h}$, however two patients in placebo group still complained of severe POST, while there was none such case in Zinc group. (Table 3) 

throat.

When comparing overall severity of POST between groups, the incidence of moderate POST was found to be statistically significant $(\mathrm{p}<0.05)$, however the overall incidence of POST in Zinc group was $26.3 \%$, which was significantly higher at $50 \%$ in placebo group. (Table 4)

\section{DISCUSSION}

Postoperative sore throat (POST) has a reported incidence of up to $62 \%$ following general anaesthesia. Adults undergoing tracheal intubation, females, young children, pre-existing lung disease and prolonged duration of anesthesia are considered to be greatest risk factors. Tracheal intubation without neuromuscular blockade, use of double-lumen tubes, as well as high tracheal tube cuff pressures may also increase the risk of postoperative sore throat. ${ }^{[11]}$ Pharyngeal, laryngeal, or tracheal irritation leading to inflammation may be the reason for POST, but it may also occur in absence of tracheal intubation. In the absence of any clearly established single mechanism which leads to POST, treatment with antiinflammatory agents (e.g., steroids and NSAIDs) to some extent help reduce its symptoms.

In the present study, administration of dispersible zinc tablet orally, $30 \mathrm{~min}$ before intubation showed lower incidence and less severity of POST at $0,30 \mathrm{~min}, 2$ hour, and 4 hour evaluation time. It may be due to the onset of anti-inflammatory action by dispersible zinc tablet which may range from 30 min to 4-6 hours based on the available data from previous studies. ${ }^{[4-6,12]} \mathrm{A}$ statistically significant difference was found between groups in our primary outcome (incidence of POST at $4 \mathrm{~h}$ ) with a $\mathrm{p}=$ 0.0012 (highly significant).The overall incidence of POST was also lower in Zinc group. This was quite similar to the outcome of the study by Sarkar et. al. ${ }^{[13]}$ and Farhang et al. ${ }^{[5]}$ This lower incidence of POST in the zinc group can be attributed to the prevention of cytokine release, decrease in reactive oxygen species, and a subsequent decrease in cyclooxygenase-2 (COX-2) expression, and prostaglandin-E2 (PGE-2) release. ${ }^{[14]}$

On comparing overall severity of POST between groups and observing the overall incidence of POST in placebo group (at 50\%) and that of Zinc group (at 26.3\%), it can be shown that almost $23.7 \%$ of patients were possibly saved by the Zinc dosage at an appropriate time preoperatively, which is significant. In absence of studies in context of natural history and duration of POST, it can be assumed that sore throat extending up-to $24 \mathrm{~h}$ and beyond, may have mechanism as that of injury, and is therefore treated as such.

The duration of action of zinc locally is not well established; for upper respiratory therapy it is recommended every $4 \mathrm{~h}$; whereas in oncologic studies, mouth washes are given every 6-12 hours. Topically applied zinc in the form of a suspension, or in the lozenge form, have been shown to be as effective as systemic therapy in prevention of mucositis and oral pain associated with chemotherapy. ${ }^{[7,15]}$ But in terms of side effects, no difference in incidences of postoperative nausea, vomiting and diarrhea between the two groups, particular to this study, was observed.

This study may carry some limitations, like small sample size and that it pertained to a shorter span of time in a single healthcare unit. Further, no pharmacokinetic data on local effects of oral dispersible zinc tablets was available to us and the dosage and time of administration time was based on previous studies only. Dispersible zinc tablets were used, because they were easily available.

\section{CONCLUSION}

A dose $40 \mathrm{mg}$ zinc dispersible tablet, equivalent to $40 \mathrm{mg}$ elemental zinc, given 30 min before surgery, effectively reduced the incidence and severity of POST, during first $4 \mathrm{~h}$ after extubation. This study further validated the potential of zinc in prevention of POST, but more such studies will be needed with larger sample size to ascertain 
Ketki Jandial et.al. Pre-operative, prophylactic use of oral zinc tablet in the management of post-operative sore throat.

the exact dosage, combinations of micronutrients, timings and frequency of administration.

\section{Acknowledgement: None}

\section{Conflict of Interest: None}

\section{Source of Funding: None}

\section{Ethical Approval: Approved}

\section{REFERENCES}

1. Lee JY, Sim WS, Kim ES, Lee SM, Kim $\mathrm{DK}, \mathrm{Na} Y \mathrm{R}$, et al. Incidence and risk factors of postoperative sore throat after endotracheal intubation in Korean patients. J Int Med Res 2017;45:744-52.

2. Najafi A, Imani F, Makarem J, Khajavi MR, Etezadi F, Habibi S, et al. Postoperative sore throat after laryngoscopy with macintosh or glide scope video laryngoscope blade in normal airway patients. Anesth Pain Med 2014;4:e15136.

3. Thomas D, Bejoy R, Zabrin N, Beevi S. Preoperative ketamine nebulization attenuate the incidence and severity of postoperative sore throat: A randomized controlled clinical trial. Saudi J Anaesth. 2018;12:440-5.

4. Borazan H, Kececioglu A, Okesli S, Otelcioglu S. Oral magnesium lozenge reduces postoperative sore throat: A randomized, prospective, placebo-controlled study. Anesthesiology 2012;117:512-8.

5. Farhang B, Grondin L. The effect of zinc lozenge on postoperative sore throat: A prospective randomized, double-blinded, placebo-controlled study. AnesthAnalg. 2018;126:78-83.

6. Truong-Tran AQ, Carter J, Ruf"n R, Zalewski PD. New insights into the role of zinc in the respiratory epithelium. Immunol Cell Biol 2001;79:170-7.

7. Hayashi H, Kobayashi R, Suzuki A, Yamada $\mathrm{Y}$, Ishida $\mathrm{M}$, Shakui $\mathrm{T}$, et al. Preparation and clinical evaluation of a novel lozenge containing polaprezinc, a
Zinc-L-carnosine, for prevention of oral mucositis in patients with hematological cancer who received high-dose chemotherapy. Med Oncol 2016;33:91.

8. Singh NP, Makkar JK, WourmsV, ZorrillaVaca A, Cappellani RB, Singh PM. Role of topical magnesium in post-operative sore throat: A systematic review and metaanalysis of randomised controlled trials. Indian J Anaesth2019;63:520-9.

9. Christensen AM, Willemoes-Larsen $\mathrm{H}$, Lundby L, Jakobsen KB. Postoperative throat complaints after tracheal intubation. Br J Anaesth1994;73:786-7.

10. Loeser EA, Bennett GM, Orr DL, Stanley TH. Reduction of postoperative sore throat with new endotracheal tube cuffs. Anesthesiology 1980;52:257-9.

11. El Boghdadly K, Bailey CR, M D Wiles MD. Postoperative sore throat: a systematic review. Anaesthesia. 2016 Jun;71(6):70617.

12. Rostan EF, DeBuys HV, Madey DL, Pinnell SR. Evidence supporting zinc as an important antioxidant for skin. Int $\mathrm{J}$ Dermatol 2002;41:606-11.

13. Sarkar T, Mandal T. Preoperative oral zinc tablet decreases incidence of postoperative sore throat. Indian J Anaesth. 2020; 64:409-14.

14. Kim J, Kim S, Jeon S, Hui Z, Kim Y, Im Y, et al. Anti-inflammatory effects of zinc in PMA-treated human gingival "broblast cells. Med Oral Patol Oral Cir Bucal 2015;20:e180-7.

15. Arbabi-kalati F, Arbabi-kalati F, Deghatipour M, Ansari Moghadam A. Evaluation of the efficacy of zinc sulfate in the prevention of chemotherapy-induced mucositis: A double-blind randomized clinical trial. Arch Iran Med 2012;15:413-7.

How to cite this article: Ketki Jandial, Shagufta Tabassum. Pre-operative, prophylactic use of oral zinc tablet in the management of postoperative sore throat. International Journal of Research and Review. 2021; 8(12): 530-534. DOI: https://doi.org/10.52403/ijrr.20211264 